\title{
Effects of Chronic Infusion of Lipopolysaccharide on Food Intake and Body Temperature of the Rat ${ }^{1}$
}

\author{
BARBARA O'REILLY, ARTHUR J. VANDER AND MATTHEW J. KLUGER ${ }^{2}$ \\ Department of Physiology, The University of Michigan Medical School \\ Ann Arbor, MI 48109
}

Received 17 August 1987

\begin{abstract}
O'REILLY, B., A. J. VANDER AND M. J. KLUGER. Effects of chronic infusion of lipopolysaccharide on food intake and body temperature of the rat. PHYSIOL BEHAV 42(3) 287-291, 1988.--Unrestrained male Sprague-Dawley rats were infused for seven days with a low $(2.45 \mu \mathrm{g} / \mathrm{hr})$ or high $(9.81 \mu \mathrm{g} / \mathrm{hr})$ concentration of $E$. coli lipopolysaccharide (LPS). Compared to control (saline-infused) rats, food intake in the LPS-infused rats remained depressed for the entire infusion period. Despite this long-term suppression of food intake, fever was observed only during the daytime hours for the first two days of infusion. No significant increase in nighttime body temperature was observed. These data indicate that although tolerance to LPS occurred in rats with regard to its fever-inducing effect, tolerance with respect to its anorexigenic action did not occur.
\end{abstract}

Biotelemetry Fever Endotoxemia Circadian rhythms Body weight Activity

ENDOTOXEMIA results in the initiation of a stereotyped host reaction termed the "acute phase response" [8, 10, 19]. Among the many metabolic, physiologic and behavioral alterations associated with the acute phase response are the development of fever $[6,13]$ and a reduction in food appetite $[5,11,15,25]$. For many years it was assumed that infection- or endotoxin-induced anorexia was the result of the development of fever (see review by Brobeck [4]); however, McCarthy et al. $[15,16]$ have shown that the reduction in food intake following the injection of lipopolysaccharide (LPS) or interleukin- 1 into rats was not related to the elevation in body temperature.

There is an extensive literature on the effects of repeated injections of LPS on the development of "tolerance"; that is, after the second or third injection of LPS, the experimental animal (generally the laboratory rabbit), no longer develops a fever (see, for example [2,26]). Roberts et al. [20] infused endotoxin into rabbits and found that some rabbits developed fevers "which lasted as long as the pump continued to operate" (ten days). In their abstract, the authors stated that the rabbits did not "appear to become tolerant to the endotoxin, as they do following repeated daily bolus injections." Other acute phase changes were apparently not measured. Fish and Spitzer [7] have performed endotoxininfusion experiments with rats, but their dose $(0.3 \mathrm{mg} / 100 \mathrm{~g}$ body weight) was large enough to produce morbidity, as indicated by the development of both hypothermia and hyperlactacidemia, a fall in hematocrit, and a progressive leu- kocytosis. This dose of endotoxin was sufficiently high to result in the death of several rats.

The present study was conducted in order to characterize the pattern of food intake, body weight, body temperature, and activity during chronic endotoxemia using doses that do not produce indications of sickness or endotoxin shock. These variables were monitored in conscious unrestrained rats for 31 days. On days 11 through 18 the rats received a continuous infusion of sterile saline or LPS.

\section{METHOD}

\section{Animals}

Eighteen specific pathogen-free male Sprague-Dawley rats weighing 150 grams at the start of the experiment were obtained from Charles River Breeding Laboratories, Inc., Portage, MI. Rats were housed individually in a temperature-controlled room at $27 \pm 1^{\circ} \mathrm{C}$, the thermoneutral zone for rats. A photoperiod of $12 \mathrm{hr}$ light $(0600$ to $1800 \mathrm{hr})$ and $12 \mathrm{hr}$ dark $(1800$ to $0600 \mathrm{hr})$ was maintained throughout the experiment. Tap water and rodent chow (Purina, 1001) were provided ad lib.

\section{Measurement of Body Temperature and Activity}

Body temperature and activity were measured using battery-operated biotelemetry devices (Model VMFH, Mini-Mitter, Inc., Sunriver, OR) implanted intraperitoneally into 9 rats three days prior to the start of the experiment.

\footnotetext{
${ }^{1}$ Research sponsored by NIH NS 23633. We thank Nicholas Mrosovsky for several helpful suggestions regarding the design of this experiment.

${ }^{2}$ Requests for reprints should be addressed to Dr. Kluger.
} 


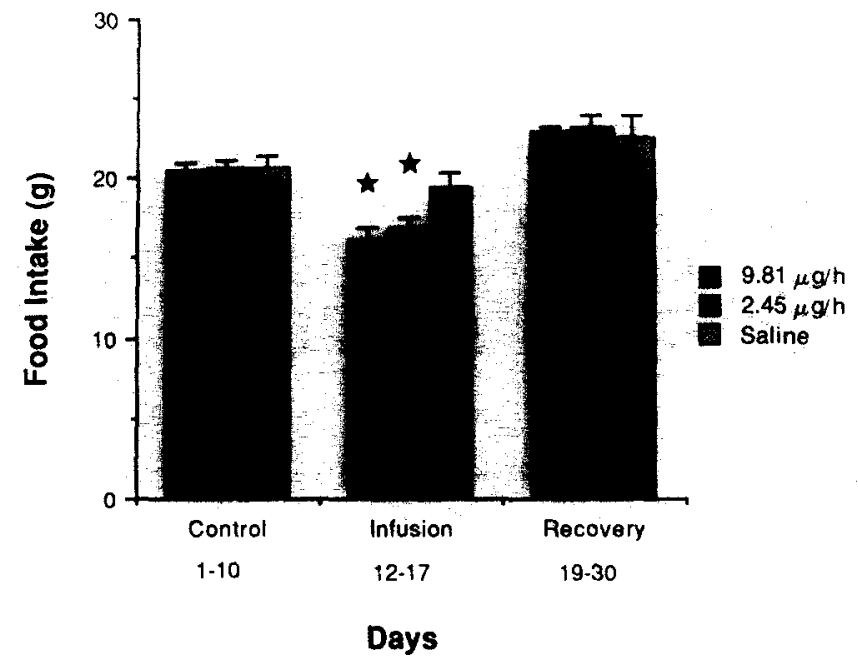

FIG. 1. Average daily food intake in rats infused with saline or LPS $(9.81 \mu \mathrm{g} / \mathrm{hr}$ or $2.45 \mu \mathrm{g} / \mathrm{hr}$ ) for Control, Infusion, and Recovery periods. Data collected on day 11 (the day of implantation of the Alzet pumps) and day 18 (theoretically, the pumps would have stopped infusing $10 \mathrm{hr}$ into this day) were omitted. Asterisks indicate significant differences from saline-infused rats.

Each transmitter was calibrated prior to implantation. Both deep body temperature and activity were monitored by signals received by a mounted antenna placed under each animal's cage and fed into a peripheral processor (Dataquest III, Data Sciences, Inc.) connected to an IBM-PC. Temperature and activity counts were recorded at 30 minute intervals 24 hours a day for 31 days. See Scales and Kluger [23] for further details regarding the telemetry system.

\section{Measurement of Food Intake and Body Weight}

Between 11:30 and 13:30 of each day all rats and their food bins were weighed using a Sartorius 1206 MP electric digital scale. Food intake was measured by subtracting the weight of the food bin on each day from the previous day. The food bins were a type that retained most of the powder that results when rats gnaw food pellets, thereby minimizing errors due to noningested food. Since there was little difference among the groups in activity, it is unlikely that there would have been significant differences among the groups in food spillage.

\section{Intraperitoneal Infusion of Bacterial Lipopolysaccharide (LPS)}

After the rats were weighed on day 10 of the experiment, they were divided into three groups so that the mean weights of the groups were within 1 gram. On day 11 , the rats were anesthetized with methoxyflurane, and Alzet osmotic pumps (2ML-1; $5-\mathrm{cm}$ length by $1.4-\mathrm{cm}$ diameter; reservoir volume $2.0 \mathrm{ml}$ ) were implanted intraperitoneally. These pumps deliver approximately 10 microliters of solution per hour for 7 days starting 4 hours post-implantation. The pumps were filled with either a sterile pyrogen-free $0.9 \%$ solution of sodium chloride (saline) or one of two concentrations of LPS (from Escherichia coli \#0111:B4, phenol extract, Sigma Chemical) in saline. The rats were moving around their cages normally and had regained normal body temperature within 4 hours following implantation.

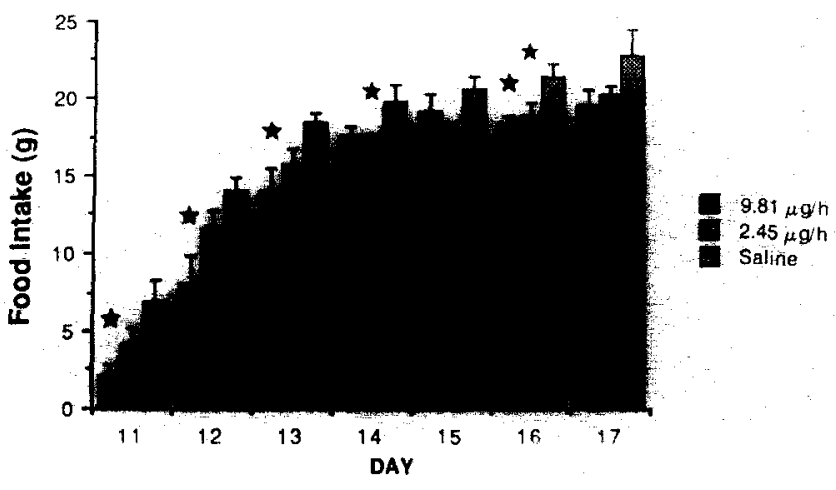

FIG. 2. Average daily food intake in rats during the 7 days of infusion with saline or LPS $(9.81 \mu \mathrm{g} / \mathrm{hr}$ or $2.45 \mu \mathrm{g} / \mathrm{hr})$. Asterisks indicate significant differences from saline-infused rats.

Six rats were implanted with saline-filled pumps (the "SAL" group). Six rats were implanted with pumps containing a LPS concentration of 250 micrograms/ml (the "LOW" group); this concentration was equivalent to an infusion rate of $2.45 \mu \mathrm{g} / \mathrm{hr}$. Six rats were implanted with pumps containing an endotoxin concentration of 1000 micrograms/ml (the "HIGH" group); this concentration was equivalent to an infusion rate of $9.81 \mu \mathrm{g} / \mathrm{hr}$. Three rats in each group had biotelemetry devices implanted prior to the start of the experiment.

\section{Data Analysis}

Day 1 to day 10 of the experiment was considered the "Control" period. Day 11 to day 18, during which time the rats were infused with saline or LPS, was considered the "Infusion" period, and days 19 through 30 were "Recovery" days. For analysis of temperature and activity data, "daytime" refers to all data collected between 06:00 and 18:00 hr; "nighttime" refers to all data collected between 18:00 and 06:00 hr. The mean change in daytime (or nighttime) body temperature during infusion was calculated by subtracting the average of the mean temperature for 12 hours on the last three control days (days 8 to 10 ), from the daytime (or nighttime) temperature for any desired infusion day. The mean relative activity during infusion was calculated by dividing the average of the raw counts on any given daytime or nighttime infusion day by the average of the mean on the last three control days (days 8 to 10). We chose the last three days prior to experimentation since this represented an extremely stable baseline to compare subsequent days.

All data were analysed using the computer service of the Michigan Terminal System. To determine whether infusion of LPS resulted in statistically significant changes in food intake, body weight, temperature or activity, the Student's $t$ test was used. For multiple comparisons, analysis of variance was used; intergroup comparisons were then made using Scheffe allowances. We have chosen only to compare food intake between LPS-infused groups and the salineinfused group. Because of the relatively small sample sizes, and the nature of statistics using ANOVA with Scheffe allowances, the decreases in food intake that were observed each day were not always statistically significant. To determine whether the rates of increase in body weight were significantly different, one-way analysis of covariance was used. All \pm values represent standard errors of the mean. 


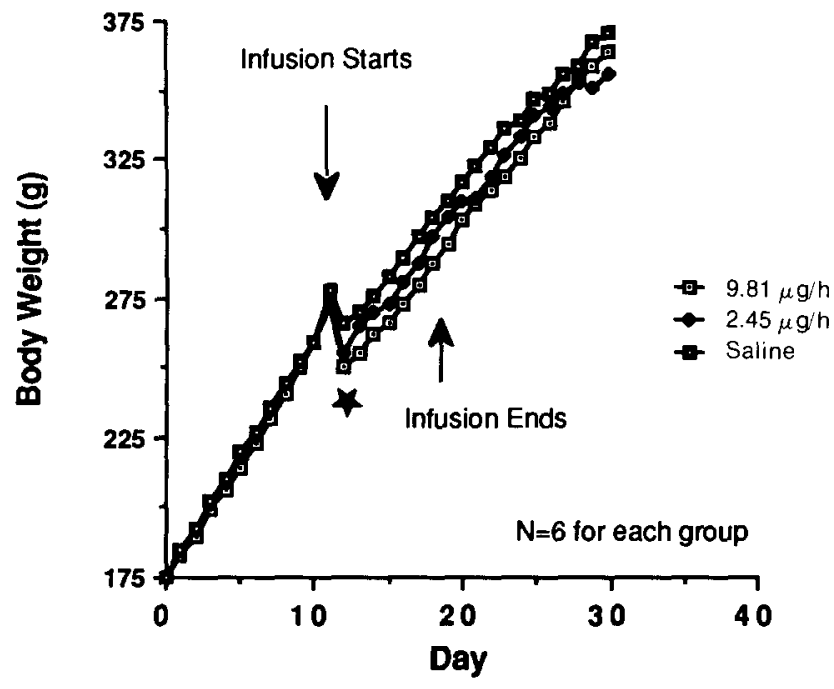

FIG. 3. Average daily body weight for rats infused with saline or with LPS $(9.81 \mu \mathrm{g} / \mathrm{hr}$ or $2.45 \mu \mathrm{g} / \mathrm{hr})$. Alzet pumps were implanted on the morning of day 11 and the infusion lasted for ca. 7 days. As terisks indicate significant differences from saline-infused rats.

\section{RESULTS}

\section{Food Intake}

During the first 10 days of the experiment (the "Control" period), food intake was not different among the 3 groups (Fig. 1). The mean daily food intake for the entire infusion period was significantly lower in both the HIGH-infused $(p<0.01)$ and LOW-infused $(p<0.02)$ compared to the SALinfused group (Student's $t$-test). During the Recovery period (day 19 through 30), food intake among the 3 groups was virtually identical. As shown in Fig. 2, food intake during the 24 hours following implantation of the Alzet pumps (day 11) fell in all three groups; however, the decline in food intake in the HIGH LPS-infused group was greater than in the SALINE-infused group. This magnitude of decrease in food intake in the HIGH LPS-infused group was generally seen on each day during the infusion period $(p<0.05$ on days 11,12 , 13, and 16, ANOVA, Scheffe allowances) (Fig. 2). For the LOW LPS-infused group food intake tended to be lower than that of the SAL-infused group on each day, but the differences were significant only on days 14 and $16(p<0.05$, ANOVA, Scheffe allowances).

\section{Body Weight}

During the "Control" period (days 0 to 10 ), the mean daily weights and the daily average weight gains of the rats in each group were similar (Fig. 3). From day 11 (when the Alzet pumps were implanted) to day 12 , the weight of the SAL rats decreased by $10.1 \pm 2.0 \mathrm{~g}$. This decrease in weight was significantly less $(p<0.01)$ (ANOVA, Scheffe allowances) than that in the HIGH group, which lost $21.5 \mathrm{~g}$ $( \pm 2.37)$, or than that in the LOW group $(p<0.05)$, which lost $19.2 \mathrm{~g}( \pm 2.1)$. During the 7 days of infusion, mean body weight of the HIGH LPS-infused group remained depressed compared to the SAL-infused group (body weight increased $12.5 \pm 5.8 \mathrm{~g}$ in the HIGH LPS-infused group compared to $30.0 \pm 3.4 \mathrm{~g}$ in the SAL-infused group; $p<0.03$, Student's $t$-test). Although the body weight of the LOW LPSinfused group tended to remain depressed compared to the

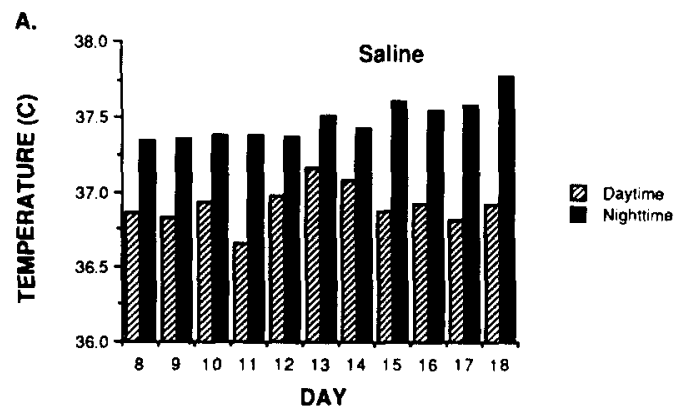

B.

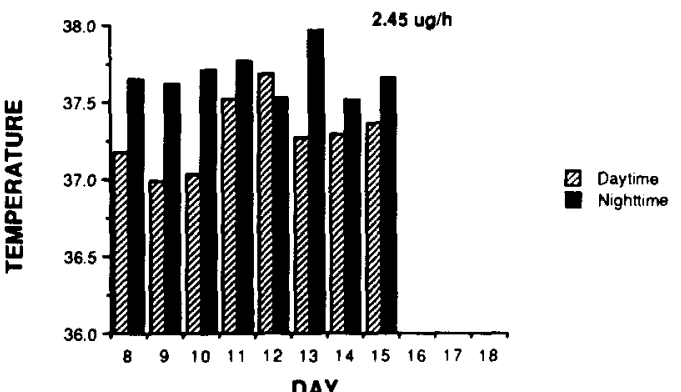

c.

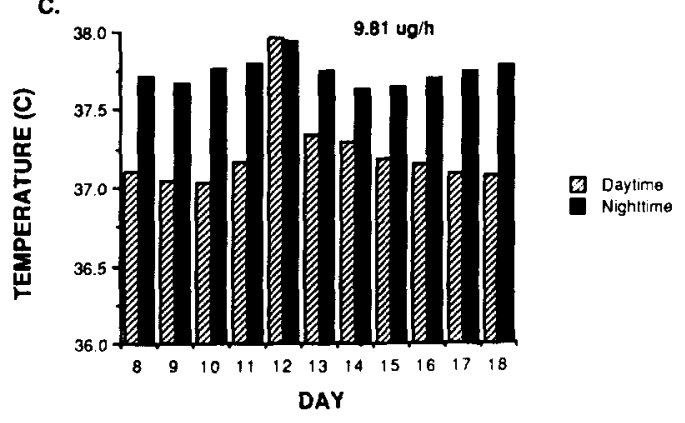

FIG. 4. Average daytime and nighttime body temperatures of rats infused with saline (A) or with LPS (B and C) $(9.81 \mu \mathrm{g} / \mathrm{hr}$ or 2.45 $\mu \mathrm{g} / \mathrm{hr}$ ). By day 15,2 of the 3 transmitters in the group receiving 2.45 $\mu \mathrm{g} / \mathrm{hr}$ LPS stopped working; as a result, data from this group are omitted for days 16 to 18 . When the batteries start to run-down, generally the temperature signals (frequency) becomes erratic; the information regarding activity seems to be transmitted for several days to weeks afterwards.

SAL-infused group, this difference was not statistically significant $(p>0.15)$. After the initial decline in body weight on day 11 to 12 , the rates of weight gain among the three groups were similar ( $p>0.66$, analysis of covariance).

\section{Body Temperature}

Rats normally have pronounced circadian rhythms in body temperature (see, for example [22-24]). The average daytime and nighttime body temperatures for rats infused with saline or LPS is shown in Fig. 4. Even though infusion of LPS resulted in a reduction in food intake and body weight for several days, the only significant differences in body temperature between the SAL-infused and LPS-infused groups occurred during the daytime hours between the SAL and LOW on days 11 (the day of surgery) and 12 , and between the SAL and HIGH on day $12(p<0.05$, ANOVA, Scheffe allowances) (Fig. 5A). Despite the continuous infusion of LPS, no significant increase in nighttime body temperature was observed (Fig. 5B). 
A.

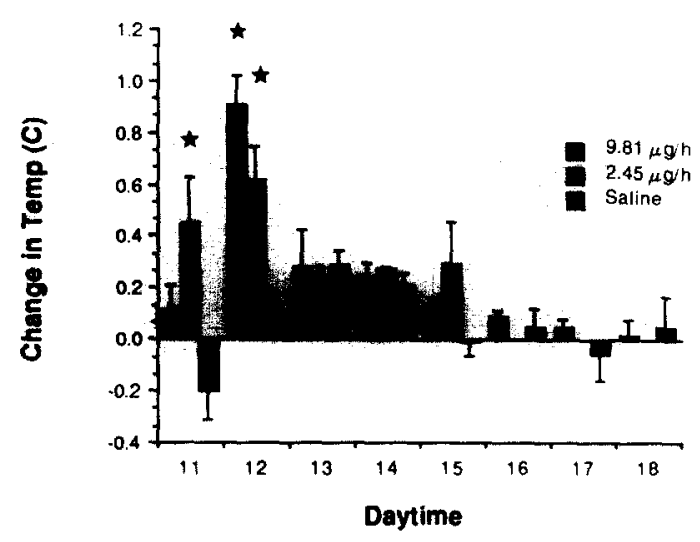

B.

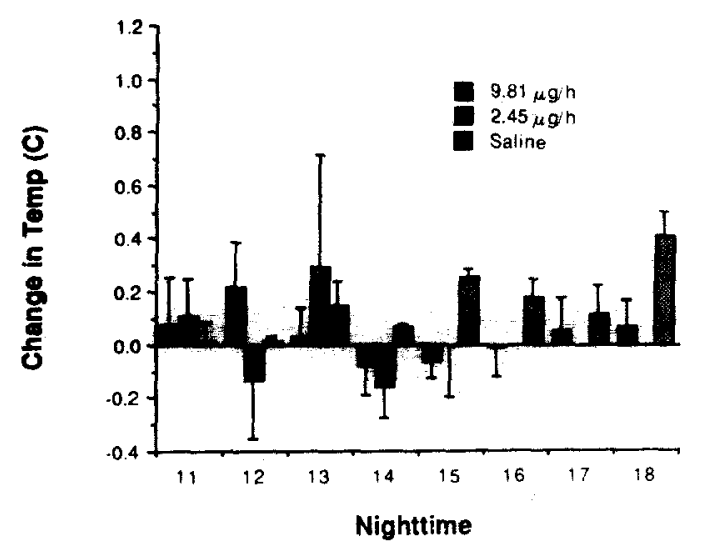

FIG. 5. Average changes in temperature for rats infused with saline or LPS $(9.81 \mu \mathrm{g} / \mathrm{hr}$ or $2.45 \mu \mathrm{g} / \mathrm{hr})$. (A) Mean daytime temperature. The mean temperature from 6:00 to $18: 00 \mathrm{hr}$ each day is subtracted from the average of 06:00 to 18:00 hr during the last three control days (days 8 to 10). Asterisks indicate significant differences from saline-infused rats. (B) Mean nighttime temperature. The mean temperature from 18:00 to 6:00 hr each night is subtracted from the average of 18:00 to 6:00 hr during the last three control days (days 8 to 10). By day 15, 2 of the 3 transmitters in the group receiving 2.45 $\mu \mathrm{g} / \mathrm{hr}$ LPS had stopped working; as a result; data from this group are omitted for days 16 to 18 .

\section{Activity}

Prior to implantation of the pumps, there were no differences in absolute activity counts among the three groups. Implantation of the Alzet pumps resulted in a reduction in nighttime activity in all three groups (Fig. 6), On day 11 (the day of surgery), there was a significantly greater decrease in relative nighttime activity in the HIGH LPS-infused group compared to the SAL-infused group $(p<0.05$, ANOVA, Scheffe allowances). After day 11, there were no significant differences among the three groups.

\section{DISCUSSION}

Infusion of LPS resulted in a rapid decrease in food intake and body weight greater than that observed in the SALinfused group. During the first 24 to $36 \mathrm{hr}$ after beginning the infusion the rats also developed a fever, but only during the daytime hours. This initial increase in body temperature (and, presumably, increase in metabolic rate) may account for part of the reduction in body weight compared to the saline-infused controls. Interestingly, even though body

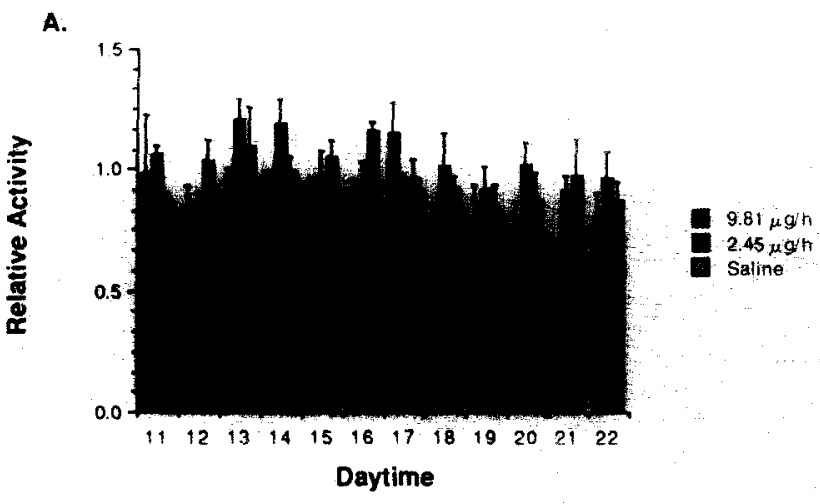

B.

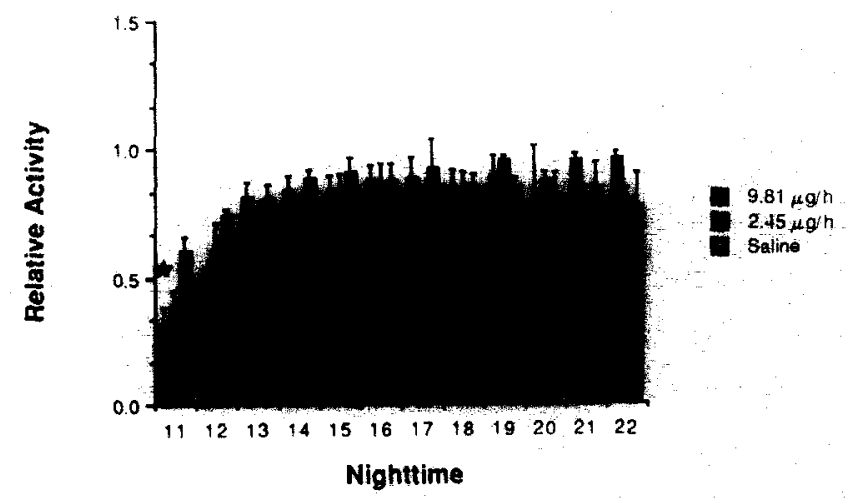

FIG. 6. Relative activity for rats infused with saline or LPS $(9.81$ $\mu \mathrm{g} / \mathrm{hr}$ or $2.45 \mu \mathrm{g} / \mathrm{hr}$ ). Values above 1.0 indicate greater activity than on control days; values below 1.0 indicate less activity than on control days. (A) Relative daytime activity. The mean activity from 6:00 to $18: 00 \mathrm{hr}$ each day is divided by the average of $06: 00$ to $18: 00 \mathrm{hr}$ during the last three control days (days 8 to 10). (B) Relative nighttime activity. The mean activity from $18: 00$ to $6: 00 \mathrm{hr}$ each night is divided by the average of $18: 00$ to $6: 00 \mathrm{hr}$ during the last three control days (days 8 to 10). Asterisks indicate significant differences from saline-infused rats.

temperature returned to normal by the second day of infusion with LPS, food intake (for both LPS-infused groups). remained lower for the seven experimental days. These results indicate that although tolerance to LPS occurred in rats with regard to its fever-inducing effect, tolerance with respect to its anorexigenic action did not occur.

Although food intake remained depressed, the rate of increase in body weight in the LPS-infused groups was virtually identical to that in the SALINE-infused group. Except for the HIGH LPS-infused group during the nighttime following implantation of the infusion pumps, activity was not significantly different between the SAL and LPS-infused groups. Therefore, these data suggest to us that the LPS-infused groups may have been more efficiently utilizing the ingested food. It is, however, important to note that the LPS-infused groups remained about $10 \mathrm{~g}$ lighter than the SALINE-infused group. It is possible that this lower body weight simply resulted in a reduction in resting metabolic rate so that weight gain was normal despite decreased food intake. It would be interesting to compare 24 hour energy expenditures between LPS- and SALINE-infused rats.

Several studies have indicated that body weight is regulated around a "set point" $[17,18]$, perhaps through the control of energy utilization. One study, by Levitsky et al. [14], showed that within a few days after food deprivation had 
ended, the body weights of rats were similar to that of controls without there being complete compensation for the loss of food that had occurred during deprivation. Several reviews document studies of the high capacity that obese mice and rats possess for retention of dietary energy $[3,9]$, and it is believed that a lower maintenance energy requirement of obese mice is a major factor contributing to their high efficiency of energy retention [21].

The infusion of LPS in the present study may have resulted in a reduction in set-point for body weight. By day 31 of the experiment, 11 days after the osmotic pumps had stopped infusing solution, the mean body weights of the two LPS groups were approaching values similar to those of the saline controls (see Fig. 3). Studies that monitor the body weight beyond 31 days would be needed to determine whether the LPS-infused groups undergo another change in set-point that brings their weight up to that of the SALINEinfused group. The suppression in food intake may have resulted from some direct actions of the LPS on the gastrointestinal tract, or indirectly through alteration in some metabolite or hormone concentration; but, despite the continued suppression in food intake, once body weight had fallen to the reduced set-point, the rate of weight gain proceeded normally.

It is interesting that despite the continued infusion of LPS, significant fevers were only observed during the daytime hours. As demonstrated here and elsewhere [22-24], body temperature is highest at night in the rat and lowest during the daylight hours. In a recent study, Scales and Kluger [23] have shown that much of rise in body tempera- ture that occurs at night can be blocked by administration of antipyretic drugs such as sodium salicylate or indomethacin, both inhibitors of prostaglandin synthesis. These drugs had no effect on daytime body temperature of rats. Based on these data, it was suggested that the circadian rhythm in body temperature might be equivalent to a cyclical fever, dependent on the synthesis of prostaglandins within the central nervous system. If both the nighttime rise in body temperature and infection- or LPS-induced fever is dependent on synthesis of prostaglandins, it is not surprising that the magnitude of the change in body temperature (i.e., fever) that occurred during the nighttime in the LPS-infused rats was smaller than this change in body temperature during the daytime. A decrease in nocturnal fever in rats injected with brewer's yeast was recently reported by Satinoff's laboratory (presented as an abstract by M. Price, S. Kent and E. Satinoff at the Neuroscience meetings, 1987). A similar circadian reduction in fever was reported by Kluger for pigeons infected with live Pasteurella multocida ([12]; see page 117). Pigeons, generally active during the daytime hours, have a pronounced rhythm in body temperature with the peak occurring during these daylight hours. During infection, the change in body temperature from control days was considerably higher during the daytime than during the nighttime. If the circadian changes in body temperature are attributable to a circadian rhythm in prostaglandins, there may also be a similar circadian rhythm in either the circulating or tissue concentration of the putative mediators of fever: interleukin-1, tumor necrosis factor, or other endogenous pyrogen.

\section{REFERENCES}

1. Beeson, P. B. Tolerance to bacterial pyrogens. I. Factors influencing its development. J Exp Med 86: 29-38, 1947.

2. Beeson, P. B. Tolerance to bacterial pyrogens. II. Role of the reticulo-endothelial system. $J$ Exp Med 86: 39-44, 1947.

3. Bray, G. A. and D. A. York. Hypothalamic and genetic obesity in experimental animals: an automatic and endocrine hypothesis. Physiol Rev 59: 719-809, 1979.

4. Brobeck, J. R. Models for analysing energy balance. In: Body Weight Regulatory System: Normal and Disturbed Mechanisms, edited by L. A. Cioffi, W. P. T. James and T. B. Van Ittalie. New York: Raven Press, 1981, pp. 1-9.

5. Buchanan, B. J. and J. P. Filkins. Insulin secretion and sensitization to endotoxin shock. Circ Shock 3: 223-230, 1975.

6. Dinarello, C. A. Interleukin-1. Rev Infect Dis 6: 51-95, 1984.

7. Fish, R. E. and J. A. Spitzer. Continuous infusion of endotoxin from an osmotic pump in the conscious, unrestrained rat: A unique model of chronic endotoxemia. Circ Shock 12: 135-149, 1984.

8. Gauldie, J., L. Lamontagne and A. Stadnyk. Acute phase response in infectious disease. Surv Synth Pathol Res 4: 126-151, 1985.

9. Herberg, L. and D. L. Coleman. Laboratory animals exhibiting obesity and diabetes syndromes. Metabolism 26: 59-99, 1977.

10. Highton, J. The acute phase response: a clinical perspective. Aust NZ J Med 14: 173-177, 1984.

11. Jepson, M. M., J. M. Pell, P. C. Bates and D. J. Millward. The effects of endotoxaemia on protein metabolism in skeletal muscle and liver of fed and fasted rats. Biochem $J$ 235: 329-336, 1986 .

12. Kluger, M. J. Fever: Its Biology, Evolution and Function. Princeton, NJ: University Press, 195 pages, 1979.

13. Kluger, M. J. Is fever beneficial? Yale J Biol Med 59: 89-95, 1986.

14. Levitsky, D. A., I. Faust and M. Glassman. The ingestion of food and the recovery of body weights following fasting in the naive rat. Physiol Behav 17: 575-580, 1976.
15. McCarthy, D. O., M. J. Kluger and A. J. Vander. The role of fever in appetite suppression after endotoxin administration. Am J Clin Nutr 40: 310-316, 1984.

16. McCarthy, D. A., M. J. Kluger and A. J. Vander. Effect of centrally administered interleukin-1 and endotoxin on food intake of fasted rats. Physiol Behav 36: 745-749, 1986.

17. Mrosovsky, N. and T. L. Powley. Set points for body weight and fat. Behav Biol 20: 205-223, 1977.

18. Mrosovsky, N. and D. F. Sherry. Animal anorexias. Science 207: $837-842,1980$.

19. Powanda, M. C. and P. G. Canonico. Infection: The Physiologic and Metabolic Responses of the Host. New York: Elsevier/ North Holland Biomedial Press, 435 pages, 1981.

20. Roberts, C. S., P. Webster, E. McClain, H. P. Laburn and D. Mitchell. Fever in rabbits during 10-day infusion of endotoxin using osmotic minipumps. S Afr $J S_{c i}$ 81: 404, 1985.

21. Romsos, D. R. Efficiency of energy retention in genetically obese animals and in dietary-induced thermogenesis. 2l Annu Ruminant Nutr Conf 2524-2529, 1981.

22. Satinoff, E. Disturbance in circadian body temperature rhythms in rats with hypothalamic damage. $J$ Therm Biol 8: 149-157, 1983.

23. Scales, W. E. and M. J. Kluger. Antipyretic drugs attenuate the circadian rise in body temperature of the rat. Am J Physiol 253: R306-R313, 1987.

24. Szymusiak, R., A. DeMory, E. M. W. Kittrell and E. Satinoff. Diurnal changes in thermoregulatory behavior in rats with medial preoptic lesions. Am J Physiol 249: R219-R227, 1985.

25. Spitzer, J. A. and R. E. Fish. Lipolytic patterns in isolated adipocytes of continuously endotoxemic rats. Circ Shock 18: 21-29, 1986

26. van Miert, A. S. J. P. A. M., J. A. J. van de Laar and C. Th. M. van Duin. Comparative observations in rabbits on fever induced by bacterial endotoxins and sodium nucleinate from yeast. $A b l \mathrm{Vet}$ Med A 23: 697-705, 1976. 